\title{
Comparison of Glycated Albumin, Hemoglobin Alc and Admission Blood Glucoseforpredictionof in- hospital Major Adverse Cardiac Events: a Retrospective Study
}

\author{
Lin Sun \\ Shandong Provincial Hospital \\ Haitao Yuan ( $\nabla$ yhtsdsl@163.com ) \\ Shandong Provincial Hospital
}

Original investigation

Keywords: acute myocardial infarction, percutaneous coronary intervention, glycated albumin, in-hospital major adverse cardiovascular events, hemoglobin A1c

Posted Date: June 30th, 2020

DOl: https://doi.org/10.21203/rs.3.rs-37479/v1

License: (c) (1) This work is licensed under a Creative Commons Attribution 4.0 International License.

Read Full License 


\section{Abstract}

Background: Hyperglycemia is an independent predictor of major adverse cardiovascular events (MACEs) in patients with acute coronary syndrome (ACS) in 30 days. The purpose of this study is to evaluate the prognostic roles of different glycemic markers for in-hospital MACEs in acute myocardial infarction (AMI) patients undergoing percutaneous coronary intervention $(\mathrm{PCl})$, including hemoglobin $\mathrm{A} 1 \mathrm{c}(\mathrm{HbA} 1 \mathrm{c})$ and glycated albumin (GA) and admission blood glucose (ABG).

Methods: We conducted a retrospective study with $200 \mathrm{Ml}$ patientswho undergone $\mathrm{PCl}$ during the hospitalization period. We collected the clinical data and divided all patients into groups based on MACEs.T test and Chi-Square (Fisher) test were conducted to examine the difference between the two groups. Univariate and Multivariate Logistic Analysis and receptor operating curve(ROC) were performed to investigate the prognostic role of each glycemic markers in AMI patients with PCI.Patients were regrouped based on ROC curve and cutoff levels. The Cox regression analysis, Kaplan Meier method and Log rank test was performed for MACEs cumulative events.

Results: Among the 200 patients, 18 patients developed MACE. Patients in MACE group had a higherdiastolic blood pressure (DBP) $(p=0.019)$, high-sensitivity troponin T (HS-TnT) peak $(p=0.011)$, CKMB peak $(p=0.026)$,myoglobin (MYO) peak $(p=0.006)$, estimated glomerular filtration rate (eGFR) $(p=0.005)$, low-density lipoprotein cholesterol $(L D L-c)(p=0.027), G A(p=0.001)$ and HbA1c $(p=0.010)$. There were more smokers $(p=0.017)$, diabetic patients $(p<0.001)$ and patients with hypertension $(p=0.009)$ in MACE group. Univariate and Multivariate logistic analysis showed GA $(p=0.029)$ and $\mathrm{HbA} 1 \mathrm{c}(\mathrm{p}=0.048)$ were independent risk factors of MACEs. ROC curve showed GA had a larger area under the curve (AUC) as prognostic marker of in-hospital MACEs $(0.743 ; 95 \%$ confidenceinterval[Cl], 0.578-0.907; $p=0.001)$ than $\mathrm{HbA} 1 \mathrm{c}(0.689 ; 95 \% \mathrm{Cl}, 0.530-0.849 ; \mathrm{p}=0.008)$ and $\mathrm{ABG}(0.593 ; 95 \% \mathrm{Cl}, 0.441-0.745 ; \mathrm{p}=0.192)$.Kaplan Meier curves showed that patients with higher levels of GA $(p=0.001), \operatorname{HbA1c}(p<0.001)$ and ABG $(p=0.008)$ had worse clinical events $(p=0.001)$.Univariate and multivariate cox regression analysis presented $G A$ has significant predictive role for MACEs.

Conclusion: Among ABG, GA and HbA1c, elevated GA were significant to predict the risk of in-hospital MACEs in AMI patients who undergone PCl during the hospitalization period.

\section{Background}

Hyperglycemia has been proved to be associated with inflammation of acute coronary syndrome [1] There are many glycemic markers to evaluate blood glucose control, including ABG, HbA1c and nontraditional markers, such as GA. Admission blood glucose only reflects the blood control at the moment, which can be affected by diet and stress. HbA1c reflects blood control over the previous 8 to 12 weeks, while GA reflects blood control during the previous 1-3 weeks [2]. Many studies have revealed the association between different glycemic markers and MACEs relatively, but few studies have compared the predictive roles in MACEs. Therefore, the aim of this study is to investigate the association between 
ABG, GA, HbA1c and in-hospital MACEs in AMI patients with PCl and identify prognostic markers in MACES.

\section{Materials And Methods}

\section{Patients and groups}

We retrospectively analyzed 200 patients who have been admitted in the Department of Cardiology of Shandong Provincial hospital from January 1, 2017 to December 31, 2019. All patients were diagnosed as acute ST segment elevated MI or acute non-ST segment elevated MI based on the American heart Association (AHA) guidelines [3], and undergone PCl. All patients with diabetes mellitus (DM) were welldiagnosed before this admission. The exclusion criteria were as follows: thyroid disease, hepatic or renal impairment, autoimmune disease and malignant tumor. Based on the in-hospital MACEs (general observation time is 7 days), patients were divided into non-MACE group and MACE group. The study protocol was proved by the medical ethic committee of Shandong Provincial Hospital.

\section{Clinical data collection}

General admission clinical characteristics including sex, age, HR, systolic blood pressure (SBP), DBP, DM, hypertension, previous Ml, previous stroke and laboratory data were recorded. Serum biochemical measurement were taken immediately at the admission, including HS-TnT, hemocyanin (HCY), blood glucose, creatinine, uric acid, triglyceride (TG), total cholesterol (TC), high-density lipoprotein cholesterol (HDL-c), LDL-C, HbA1c and GA. The peak HS-TnT were the maximum value during hospitalization. MACEs were defined as cardiac death, malignant arrhythmia, unstable angina pectoris, acute heart failure and

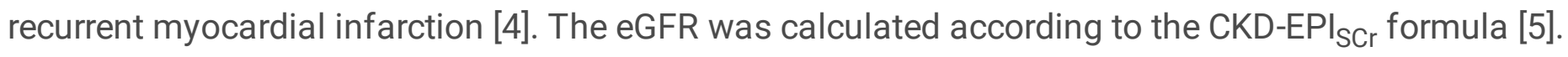

\section{Statistical analysis}

All data analysis was conducted by SPSS version 21.0. Continuous variables were expressed as mean $\pm S D$ and undergone independent-samples $t$-test. Categorical variables were expressed as number[percentage] and undergone chi-square test or Fisher exact test. Univariate and multivariate logistic regression analysis were performed to determine risk factors of MACEs. ROC curve was constructed to determine the prognostic role of $A B G, H b A 1 c$ and $G A$. According tothe cutoff value of $A B G$, $\mathrm{GA}$ and $\mathrm{HbA} 1 \mathrm{c}$, patients were divided into two groups relatively, which are defined as follows: Group $1 \mathrm{~A}$, patients with $A B G$ value $<6.51$, Group 1B, patients with $A B G$ value $\geq 6.51$; Group 2A, patients with $G A$ value $<23.54$, Group 2B, patients with GA value $\geq 23.54$; Group3A, patients with $\mathrm{HbA} 1 \mathrm{c}$ value $<7.46$, Group $3 B$, patients with $\mathrm{HbA1c}$ value $\geq 7$.46.Kaplan Meier curve and Log Rank test were conducted for MACEs. A two-side $p<0.05$ was considered significant.

\section{Results}

1. Clinical characteristics of all patients 
We collected clinical data of $200 \mathrm{AMI}$ patients who undergone $\mathrm{PCl}$, which were presented in Table 1. Compared with non-MACE group, patients with MACEs had higher percentage of female $(p=0.019)$, HS$\operatorname{TnT}(p=0.011), \operatorname{CKMB}(p=0.026), \mathrm{MYO}(p=0.006), \mathrm{GA}(p=0.001), \mathrm{HbA1c}(p=0.010)$ and lowerDBP $(p=0.019)$, eGFR $(p=0.005), L D L-c(p=0.027)$. There are more patients with history of smoking $(p=0.017)$, diabetes $(p<0.001)$ and hypertension $(p=0.009)$ in MACE group than non-MACE group.There were no significant differences seen between the two groups in age, heart rate, systolic blood pressure, homocysteine, creatinine, uric acid, triglyceride, total cholesterol, high density lipoprotein cholesterol (HDL-C), history of previous $\mathrm{MI}, \mathrm{PCl}, \mathrm{CABG}$ and stroke.

2. Univariate and multivariate logistic regression analysis of all factors

Univariate and multivariate logistic regression analysis revealedthat there were significant differences between non-MACE group and MACE group in terms of sex, smoking, diabetes, hypertension, HR, DBP, HsTnT, CKMB, MYO, eGFR, HbA1c and GA. Multivariate logistic regression analysis showed $\mathrm{HbA1c}$ $(p=0.048)$ and $G A(p=0.029)$ were independent risk factors contributing to MACEs (Table 2).

\section{Prognostic accuracy of GA for MACEs}

Figure 1 presented that GA had a larger AUC $(0.743 ; 95 \% \mathrm{Cl}, 0.578-0.907 ; \mathrm{p}=0.001)$ than blood glucose $(0.593 ; 95 \% \mathrm{Cl}, 0.441-0.745 ; \mathrm{p}=0.192)$ and $\mathrm{HbA} 1 \mathrm{c}(0.689 ; 95 \% \mathrm{Cl}, 0.530-0.849 ; \mathrm{p}=0.008)$. The cutoff values of $A B G, H b A 1 c$ and $G A$ in ROC curve were6.51 (sensitivity, 33.3\%; specificity, 65.9\%), 7.46 (sensitivity, 61.1\%; specificity, 85.7\%) and 23.54 (sensitivity, 33.3\%; specificity, 96.2\%) relatively.

\section{In-hospital outcomes}

In the univariate cox regression analysis, sex, smoking, DM, HBP, HR, DBP, CKMB, HS-TnT, MYO, eGFR, GA and $\mathrm{HbA} 1 \mathrm{c}$ were associated with MACEs. Multivariate cox analysis showed that $\mathrm{GA}(\mathrm{p}<0.001)$ and MYO $(p=0.027)$ were significant predictive markers for MACEs (Table 3$)$.Kaplan Meier curves showed that patients with higher levels of GA had worse clinical events $(p=0.001)$ (Figure 2-4).

\section{Discussion}

Many studies have confirmed that abnormal blood glucose control is associated with incidence of MACEs in ACS patients. Those findings showed admission blood glucose, HbA1c and non-traditional glycemic markers may be independent risk factors for MACEs within long-term and short-term follow-up [6-10]. MostafaAlavi et al. [11] demonstrated that abnormal ABG in ACS patients was an independent predictor of MACEs within 30 days. Chi Yuen Chan et al. [12] found that admission HbA1c levels were not associated with short-term MACEs in diabetic patients with ACS. Few studies have conducted to figure out the prognostic role of $\mathrm{GA}, \mathrm{ABG}$ and $\mathrm{HbA1c}$ for in-hospital MACEs.

The aim of our study was to investigate the predictive ability of ABG, GA and HbA1c for MACEs in AMI patients who undergone $\mathrm{PCl}$ during hospitalization.Our study has showed that patients in MACE group had higher GA and HbA1c, compared with non-MACE group, while ABG showed no significant 
difference.Logistic regression analysis showed that GA, as well as $\mathrm{HbA1c}$ were independent risk factors for MACEs. In order to compare predictive abilities of these glycemic markers, we performed ROC curve, identified the cutoff values and regrouped all patients. Kaplan Meier curve showed that patients with GA value $\geq 23.54$ had worse clinical outcomes than higher level of $\mathrm{HbA} 1 \mathrm{c}$ and $\mathrm{ABG}$. Cox regression analysis revealed that GA is the only predictive markers for in-hospital worse clinical events among these glycemic products.

Admission blood glucose can be affected by many factors, including diet, stress response and sympathetic activation [13]. Although ABG and heart rate has been proved to be associated stress response, which leads to vascular endothelial dysfunction and poor prognosis, stress hyperglycemia is a transient increase of blood glucose [14]. Blood glucose may not at the peak when blood sampleswere collected, which leading to weak correlation between ABG and MACEs.HbA1c is a reliable monitor for diabetic control during the previous 8-12weeks, which reflects general glucose metabolism. Therefore, the $\mathrm{HbA1c}$ level is not influenced by stress and acute inflammation. Thus, HbA1c may not be a marker for inhospital poor clinical outcome.

Glycated albumin is a reflection of the preceding 8-12 weeks. Hepatic and renal dysfunction, inflammation and acute infection may affect GA [15]. In this study, we found that GA had predictive role for in-hospital MACEs in AMI patients who undergone PCl during hospitalization. We confirmed that GA may reflect the acute inflammation in AMI patients with PCl, which suggests that increase of GA may be driven by acute myocardial infarction.

There were also some limitations in this study. First, only patients with detection of $\mathrm{HbA} 1 \mathrm{c}$ and GA during admission were enrolled, which may cause selective bias.Second, our study is a cross-sectional study and cannot determine the causal relationship between GA and AMI, which is worthy further study in the future.

\section{Conclusion}

We found that GA was significant independent risk factors for in-hospitals MACEs. HbA1c and admission blood glucose were not associated with poor in-hospital clinical outcomes in AMI patients undergone PCI. Our findings may provide anon-traditional marker for predicting MACEs during hospitalization.

\section{Abbreviations}

MACE: major adverse cardiovascular events; ACS: acute coronary syndrome; AMI: acute myocardial infarction; PCl: percutaneous coronary intervention; HbA1c: hemoglobin A1c; GA: glycated albumin; ABG: admission blood glucose; ROC: receptor operating curve; DBP: diastolic blood pressure; HS-TnT: highsensitivity troponin T; MYO: myoglobin; eGFR: estimated glomerular filtration rate; LDL-c: low-density lipoprotein cholesterol; AUC: area under the curve; Cl: confidence interval; AHA: American heart Association; DM: diabetes mellitus; SBP: systolic blood pressure; $\mathrm{HCY}$ : hemocyanin; triglyceride (TG), total 
cholesterol (TC), high-density lipoprotein cholesterol (HDL-C); TG: triglyceride; TC: total cholesterol; HDL-C: high-density lipoprotein cholesterol;

\section{Declaration}

\section{Ethics approval and consent to participate}

The study was approved by the medical ethic committee of Shandong Provincial Hospital.

\section{Consent for publication}

Not applicable.

\section{Availability of data and raw materials}

The data analysed in this study are available from the corresponding author on reasonable request.

\section{Competing interests}

The authors declared no conflicts of interest.

\section{Funding}

None.

\section{Authors' contribution}

LS designed the study andanalysed the data. LS and HTY wrote the manuscript. All authors read and approved the final manuscript.

\section{Acknowledgement}

Not applicable.

\section{Authorship information}

${ }^{1}$ Department of Cardiovascular Disease, Shandong Provincial Hospital affiliated to Shandong University, Jinan, PR China.

\section{References}

[1] Winzap P, Davies A, Klingenberg R, et al. Diabetes and baseline glucose are associated with inflammation, left ventricular function and short- and long-term outcome in acute coronary syndromes: role of the novel biomarker Cyr 61. Cardiovasc Diabetol. 2019;18(1):142. 
[2] Wen J, Hu F, Yang Q. Comparison of Hemoglobin Alc, Glycated Albumin and Fasting Plasma Glucose for Prediction of Arterial Stiffness in Chinese Adults. Diabetes MetabSyndrObes. 2020;13:65-70.

[3] Jneid H, Bozkurt B, Fonarow GC. The 2017 AHA/ACC Performance and Quality Measures for Patients With Acute Myocardial Infarction. JAMA Cardiol. 2018;3(7):659-660.

[4] Ye L, Bai HM, Jiang D, et al. Combination of eosinophil percentage and high-sensitivity C-reactive protein predicts in-hospital major adverse cardiac events in ST-elevation myocardial infarction patients undergoing primary percutaneous coronary intervention [published online ahead of print, 2020 May 22]. $J$ Clin Lab Anal. 2020;e23367.

[5] Ma YC, Zuo L, Chen JH, et al. Modified glomerular filtration rate estimating equation for Chinese patients with chronic kidney disease [published correction appears in J Am Soc Nephrol. 2006 Dec;17(12):3540]. J Am Soc Nephrol. 2006;17(10):2937-2944.

[6] White HD, Stewart RAH, Dalby AJ, et al. In patients with stable coronary heart disease, low-density lipoprotein-cholesterol levels $<70 \mathrm{mg} / \mathrm{dL}$ and glycosylated hemoglobin $\mathrm{A} 1 \mathrm{c}<7 \%$ are associated with lower major cardiovascular events. Am Heart J. 2020;225:97-107.

[7] Giugliano D, Bellastella G, Longo M, et al. Relationship between improvement of glycaemic control and reduction of major cardiovascular events in 15 cardiovascular outcome trials: A meta-analysis with metaregression [published online ahead of print, 2020 Apr 6]. Diabetes ObesMetab. 2020;10.1111/dom.14047.

[8] Zhao Q, Zhang T, Cheng Y, et al. Prognostic significance of relative hyperglycemia after percutaneous coronary intervention in patients with and without recognized diabetes [published online ahead of print, 2020 Mar 17]. CurrVascPharmacol. 2020;10.2174/1570161118666200317145540.

[9] Turgeon RD, Koshman SL, Youngson E, Pearson GJ. Association Between Hemoglobin A1c and Major Adverse Coronary Events in Patients with Diabetes Following Coronary Artery Bypass Surgery. Pharmacotherapy. 2020;40(2):116-124.

[10] Bessonov IS, Kuznetsov VA, Ziryanov IP, Sapozhnikov SS, Potolinskaya YV. Kardiologiia. 2019;59(3S):16-22.

[11] Alavi-Moghaddam M, Parsa-Mahjoob M, Ghodssi-Ghassemabadi R, Bitazar B. Association of Admission Blood Glucose Level with Major Adverse Cardiac Events in Acute Coronary Syndrome; a Cohort Study. Arch AcadEmerg Med. 2019;7(1):e26.

[12] Chan CY, Li R, Chan JY, et al. The value of admission $\mathrm{HbA}(1 \mathrm{c})$ level in diabetic patients with acute coronary syndrome. Clin Cardiol. 2011;34(8):507-512.

[13] Li Y, Li X, Zhang Y, et al. Impact of glycemic control status on patients with ST-segment elevation myocardial infarction undergoing percutaneous coronary intervention. BMC Cardiovasc Disord. 2020;20(1):36. 
[14] Zhou YD, Yuan HW, Ji RJ, Luo BY. Correlation of Stress Hyperglycemia after Ischemic Stroke with Early Vascular Cognitive Impairment. Zhongguo Yi XueKeXue Yuan Xue Bao. 2017;39(6):749-755.

[15] Song SO, Kim KJ, Lee BW, Kang ES, Cha BS, Lee HC. Serum glycated albumin predicts the progression of carotid arterial atherosclerosis. Atherosclerosis. 2012;225(2):450-455.

\section{Tables}




\section{Table 1. Baseline Characteristics of Patients in non-MACE and MACE group.}

\begin{tabular}{|c|c|c|c|}
\hline & $\begin{array}{l}\text { Non-MACE group } \\
(n=182)\end{array}$ & $\begin{array}{l}\text { MACE group } \\
(n=18)\end{array}$ & $p$ \\
\hline Age (years) & $60.59 \pm 12.03$ & $66.33 \pm 12.00$ & 0.055 \\
\hline sex & & & 0.019 \\
\hline Female [n (\%)] & $36(19.8 \%)$ & $9(50.0 \%)$ & \\
\hline Male [n (\%)] & $146(80.2 \%)$ & $9(50.0 \%)$ & \\
\hline $\mathrm{DM}[\mathrm{n}(\%)]$ & $45(24.7 \%)$ & $12(66.7 \%)$ & $<0.001$ \\
\hline HBP [n (\%)] & $121(66.5 \%)$ & $6(33.3 \%)$ & 0.009 \\
\hline Smoking [n (\%)] & $93(51.1 \%)$ & $4(22.2 \%)$ & 0.017 \\
\hline Heart rate (beats/min) & $73.37 \pm 12.57$ & $80.83 \pm 15.02$ & 0.055 \\
\hline $\mathrm{SBP}(\mathrm{mmHg})$ & $130.73 \pm 19.13$ & $128.67 \pm 24.21$ & 0.671 \\
\hline $\mathrm{DBP}(\mathrm{mmHg})$ & $76.48 \pm 10.86$ & $70.17 \pm 10.77$ & 0.019 \\
\hline $\mathrm{HS}-\mathrm{TnT}(\mathrm{pg} / \mathrm{mL})$ & $568.98 \pm 1227.35$ & $1855.04 \pm 1888.31$ & 0.011 \\
\hline CKMB (ng/mL) & $14.01 \pm 38.77$ & $53.00 \pm 67.36$ & 0.026 \\
\hline MYO (ng/mL) & $54.54 \pm 102.73$ & $257.80 \pm 272.86$ & 0.006 \\
\hline $\mathrm{HCY}(\mu \mathrm{mol} / \mathrm{L})$ & $15.49 \pm 7.78$ & $12.35 \pm 2.73$ & 0.091 \\
\hline Blood glucose (mmol/L) & $6.59 \pm 2.30$ & $7.20 \pm 2.10$ & 0.273 \\
\hline Creatinine $(\mu \mathrm{mol} / \mathrm{L})$ & $73.46 \pm 19.49$ & $73.67 \pm 5.43$ & 0.916 \\
\hline eGFR & $94.06 \pm 18.08$ & $81.33 \pm 17.58$ & 0.005 \\
\hline Uric $\operatorname{acid}(\mu \mathrm{mol} / \mathrm{L})$ & $347.87 \pm 109.96$ & $354.67 \pm 210.50$ & 0.894 \\
\hline Triglyceride (mmol/L) & $1.70 \pm 0.83$ & $1.33 \pm 0.67$ & 0.071 \\
\hline Total cholesterol $(\mathrm{mmol} / \mathrm{L})$ & $4.38 \pm 1.12$ & $3.93 \pm 0.85$ & 0.096 \\
\hline $\mathrm{HDL}-\mathrm{c}(\mathrm{mmol} / \mathrm{L})$ & $1.03 \pm 0.23$ & $1.08 \pm 0.15$ & 0.275 \\
\hline LDL-c (mmol/L) & $2.79 \pm 0.94$ & $2.47 \pm 0.49$ & 0.027 \\
\hline $\mathrm{GA}(\%)$ & $15.93 \pm 4.05$ & $23.71 \pm 8.53$ & 0.001 \\
\hline $\mathrm{HbA1c}(\%)$ & $6.09 \pm 1.36$ & $7.34 \pm 1.80$ & 0.010 \\
\hline \multicolumn{4}{|l|}{ Disease history } \\
\hline Previous MI [n (\%)] & $17(9.3 \%)$ & $0(0.0 \%)$ & 0.323 \\
\hline
\end{tabular}




\begin{tabular}{|llll|} 
Previous PCI [n (\%)] & $7(3.8 \%)$ & $0(0.0 \%)$ & 1.000 \\
\hline Previous CABG [n (\%)] & $0(0.0 \%)$ & $0(0.0 \%)$ & a* \\
\hline Previous stroke [n (\%)] & $30(16.5 \%)$ & $3(16.7 \%)$ & 1.000 \\
* a is a constant. & & & \\
\hline
\end{tabular}




\begin{tabular}{|c|c|c|c|c|}
\hline \multirow[t]{2}{*}{ Variable } & \multicolumn{2}{|l|}{ Univariate Analysis } & \multicolumn{2}{|l|}{ Multivariate Analysis } \\
\hline & OR $(95 \% \mathrm{Cl})$ & $p$ & OR $(95 \% \mathrm{Cl})$ & $p$ \\
\hline Age (years) & $1.045(0.999,1.093)$ & 0.058 & Not Selected & \\
\hline sex & $4.056(1.502,10.951)$ & 0.006 & $6.452(0.068,60.836)$ & 0.422 \\
\hline $\mathrm{DM}[\mathrm{n}(\%)]$ & $6.089(2.160,17.162)$ & 0.001 & $175.540(0.000,1103.892)$ & 0.448 \\
\hline HBP [n (\%)] & $0.252(0.090,0.704)$ & 0.009 & $5.542(0.013,22.995)$ & 0.578 \\
\hline Smoking [n (\%)] & $0.273(0.087,0.862)$ & 0.027 & $1.205(0.002,7.072)$ & 0.954 \\
\hline Heart rate (beats/min) & $1.041(1.006,1.078)$ & 0.023 & $0.998(0.789,1.263)$ & 0.990 \\
\hline $\mathrm{SBP}(\mathrm{mmHg})$ & $0.995(0.970,1.019)$ & 0.669 & Not Selected & \\
\hline $\mathrm{DBP}(\mathrm{mmHg})$ & $0.944(0.898,0.992)$ & 0.022 & $0.736(0.512,1.059)$ & 0.099 \\
\hline HS-TnT(pg/mL) & $1.000(1.000,1.001)$ & 0.002 & $1.001(0.999,1.004)$ & 0.255 \\
\hline CKMB (ng/mL) & $1.011(1.004,1.019)$ & 0.003 & $1.020(0.949,1.097)$ & 0.589 \\
\hline MYO (ng/mL) & $1.005(1.003,1.008)$ & $<0.001$ & $1.016(0.998,1.034)$ & 0.085 \\
\hline $\mathrm{HCY}(\mu \mathrm{mol} / \mathrm{L})$ & $0.869(0.750,1.006)$ & 0.061 & Not Selected & \\
\hline Blood glucose (mmol/L) & $1.113(0.919,1.348)$ & 0.275 & Not Selected & \\
\hline Creatinine $(\mu \mathrm{mol} / \mathrm{L})$ & $1.001(0.975,1.027)$ & 0.965 & Not Selected & \\
\hline eGFR & $0.962(0.936,0.989)$ & 0.006 & $0.893(0.754,1.059)$ & 0.193 \\
\hline Uric $\operatorname{acid}(\mu \mathrm{mol} / \mathrm{L})$ & $1.000(0.997,1.004)$ & 0.821 & Not Selected & \\
\hline $\mathrm{TG}(\mathrm{mmol} / \mathrm{L})$ & $0.453(0.192,1.072)$ & 0.072 & Not Selected & \\
\hline $\mathrm{TC}(\mathrm{mmol} / \mathrm{L})$ & $0.656(0.397,1.081)$ & 0.098 & Not Selected & \\
\hline HDL-c (mmol/L) & $2.353(0.287,19.303)$ & 0.426 & Not Selected & \\
\hline LDL-c (mmol/L) & $0.646(0.349,1.196)$ & 0.164 & Not Selected & \\
\hline GA (\%) & $1.244(1.141,1.357)$ & $<0.001$ & $6.768(1.216,37.678)$ & 0.029 \\
\hline HbA1c (\%) & $9.429(3.351,26.532)$ & $<0.001$ & $0.008(0.001,0.959)$ & 0.048 \\
\hline \multicolumn{5}{|l|}{ Disease history } \\
\hline Previous MI [n (\%)] & $a^{*}$ & 0.998 & Not Selected & \\
\hline Previous PCI [n (\%)] & $a^{*}$ & 0.099 & Not Selected & \\
\hline Previous CABG [n (\%)] & $b^{\star}$ & & Not Selected & \\
\hline
\end{tabular}


Previous stroke $[\mathrm{n}(\%)] \quad 1.013(0.276,3.718) \quad 0.984 \quad$ Not Selected

* $\mathrm{a}$ is not applicable. $\mathrm{b}$ is a constant. 


\begin{tabular}{|c|c|c|c|c|}
\hline \multirow[t]{2}{*}{ Variable } & \multicolumn{2}{|l|}{ Univariate Analysis } & \multicolumn{2}{|l|}{ Multivariate Analysis } \\
\hline & OR $(95 \% \mathrm{Cl})$ & $p$ & OR $(95 \% \mathrm{Cl})$ & $p$ \\
\hline Age (years) & $1.045(1.000,1.091)$ & 0.050 & Not Selected & \\
\hline sex & $3.737(1.483,9.418)$ & 0.005 & $5.450(0.609,48.794)$ & 0.130 \\
\hline $\mathrm{DM}[\mathrm{n}(\%)]$ & $5.599(2.100,14.926)$ & 0.001 & $0.059(0.001,4.386)$ & 0.198 \\
\hline HBP [n (\%)] & $0.270(0.101,0.719)$ & 0.009 & $0.804(0.147,4.409)$ & 0.802 \\
\hline Smoking [n (\%)] & $0.290(0.095,0.881)$ & 0.029 & $0.748(0.161,3.483)$ & 0.712 \\
\hline Heart rate (beats/min) & $1.039(1.006,1.073)$ & 0.019 & $0.988(0.924,1.056)$ & 0.717 \\
\hline $\mathrm{SBP}(\mathrm{mmHg})$ & $0.995(0.972,1.019)$ & 0.709 & Not Selected & \\
\hline $\mathrm{DBP}(\mathrm{mmHg})$ & $0.947(0.904,0.991)$ & 0.020 & $0.922(0.838,1.015)$ & 0.096 \\
\hline HS-TnT(pg/mL) & $1.000(1.000,1.000)$ & 0.001 & $1.001(1.000,1.003)$ & 0.064 \\
\hline CKMB (ng/mL) & $1.008(1.003,1.014)$ & 0.002 & $0.989(0.952,1.027)$ & 0.567 \\
\hline MYO (ng/mL) & $1.004(1.003,1.006)$ & $<0.001$ & $1.005(1.001,1.030)$ & 0.027 \\
\hline $\mathrm{HCY}(\mu \mathrm{mol} / \mathrm{L})$ & $0.879(0.767,1.006)$ & 0.061 & Not Selected & \\
\hline Blood glucose (mmol/L) & $1.100(0.920,1.314)$ & 0.295 & Not Selected & \\
\hline Creatinine $(\mu \mathrm{mol} / \mathrm{L})$ & $1.001(0.976,1.025)$ & 0.968 & Not Selected & \\
\hline eGFR & $0.965(0.942,0.989)$ & 0.005 & $0.981(0.934,1.030)$ & 0.432 \\
\hline Uric $\operatorname{acid}(\mu \mathrm{mol} / \mathrm{L})$ & $1.000(0.996,1.004)$ & 0.875 & Not Selected & \\
\hline TG (mmol/L) & $0.456(0.197,1.054)$ & 0.066 & Not Selected & \\
\hline $\mathrm{TC}(\mathrm{mmol} / \mathrm{L})$ & $0.672(0.419,1.076)$ & 0.098 & Not Selected & \\
\hline $\mathrm{HDL}-\mathrm{c}(\mathrm{mmol} / \mathrm{L})$ & $2.158(0.299,15.561)$ & 0.445 & Not Selected & \\
\hline LDL-c (mmol/L) & $0.666(0.373,1.188)$ & 0.168 & Not Selected & \\
\hline GA (\%) & $1.243(1.158,1.335)$ & $<0.001$ & $1.773(1.294,2.430)$ & $<0.001$ \\
\hline HbA1c (\%) & $1.460(1.181,1.804)$ & $<0.001$ & $0.501(0.211,1.192)$ & 0.118 \\
\hline \multicolumn{5}{|l|}{ Disease history } \\
\hline Previous MI [n (\%)] & $0.043(0.000,55.112)$ & 0.389 & Not Selected & \\
\hline Previous PCI [n (\%)] & $0.047(0.000,2691.184)$ & 0.584 & Not Selected & \\
\hline Previous CABG [n (\%)] & $a^{\star}$ & & Not Selected & \\
\hline
\end{tabular}


Previous stroke $[n(\%)] \quad 0.933(0.305,3.644) \quad 0.933 \quad$ Not Selected

* $\mathrm{a}$ is a constant.

Figures

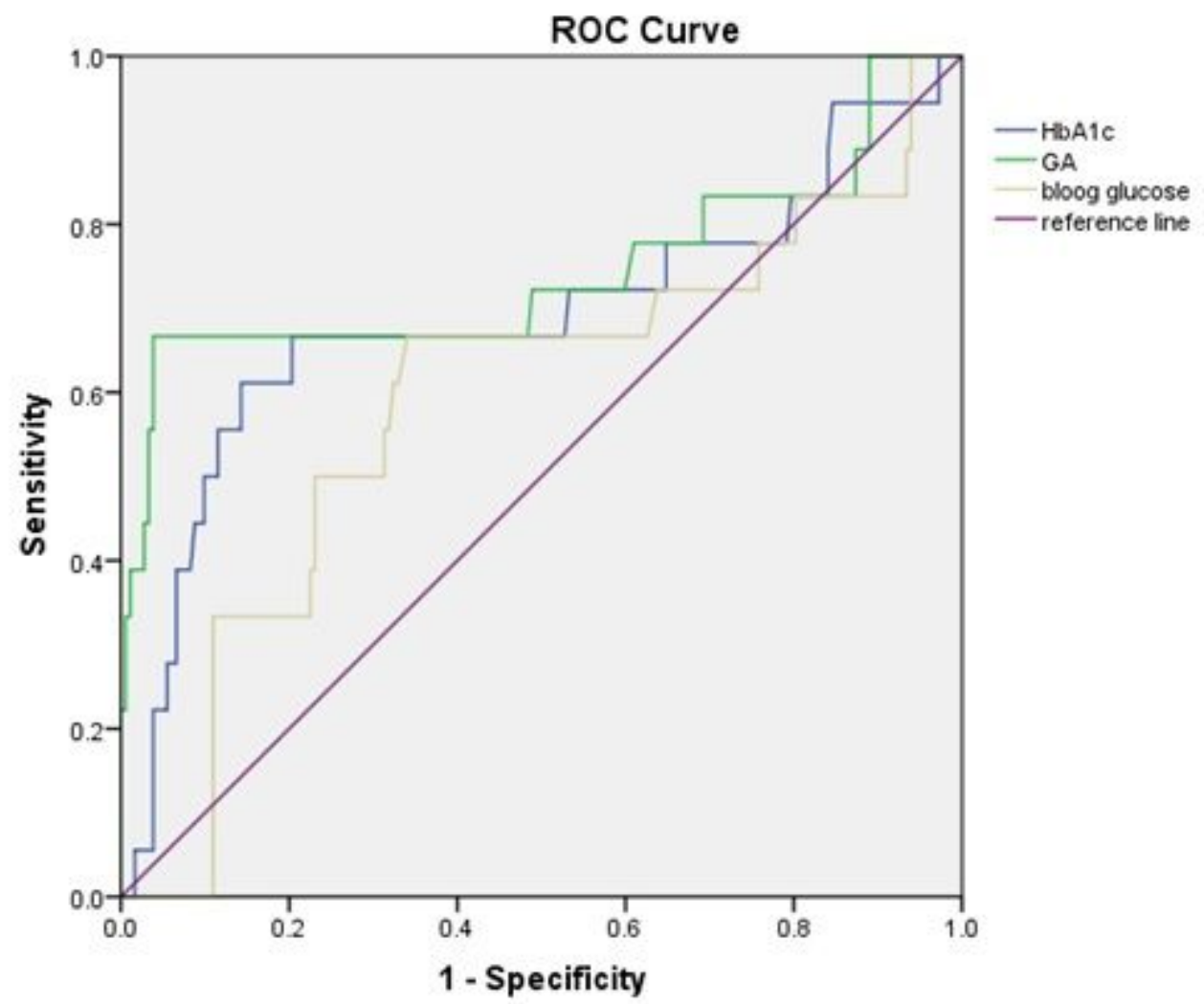

Figure 1.

\section{Figure 1}

ROC curves of HbA1c, GA and ABG. The AUC of GA is $0.743(95 \% \mathrm{Cl}, 0.578-0.907 ; \mathrm{p}=0.001)$. The AUC of $A B G$ is $0.593(95 \% \mathrm{Cl}, 0.441-0.745 ; p=0.192)$. The $A U C$ of $\mathrm{HbA} 1 \mathrm{c}$ is $0.689(95 \% \mathrm{Cl}, 0.530-0.849 ; \mathrm{p}=0.008)$. The cutoff value of GAis 23.54 (sensitivity, 33.3\%; specificity, $96.2 \%$ ). The cutoff valueof ABG is 6.51 (sensitivity, $33.3 \%$; specificity, $65.9 \%$ ). The cutoff value of $\mathrm{HbA1c}$ is 7.46 (sensitivity, $61.1 \%$; specificity, $85.7 \%)$. 


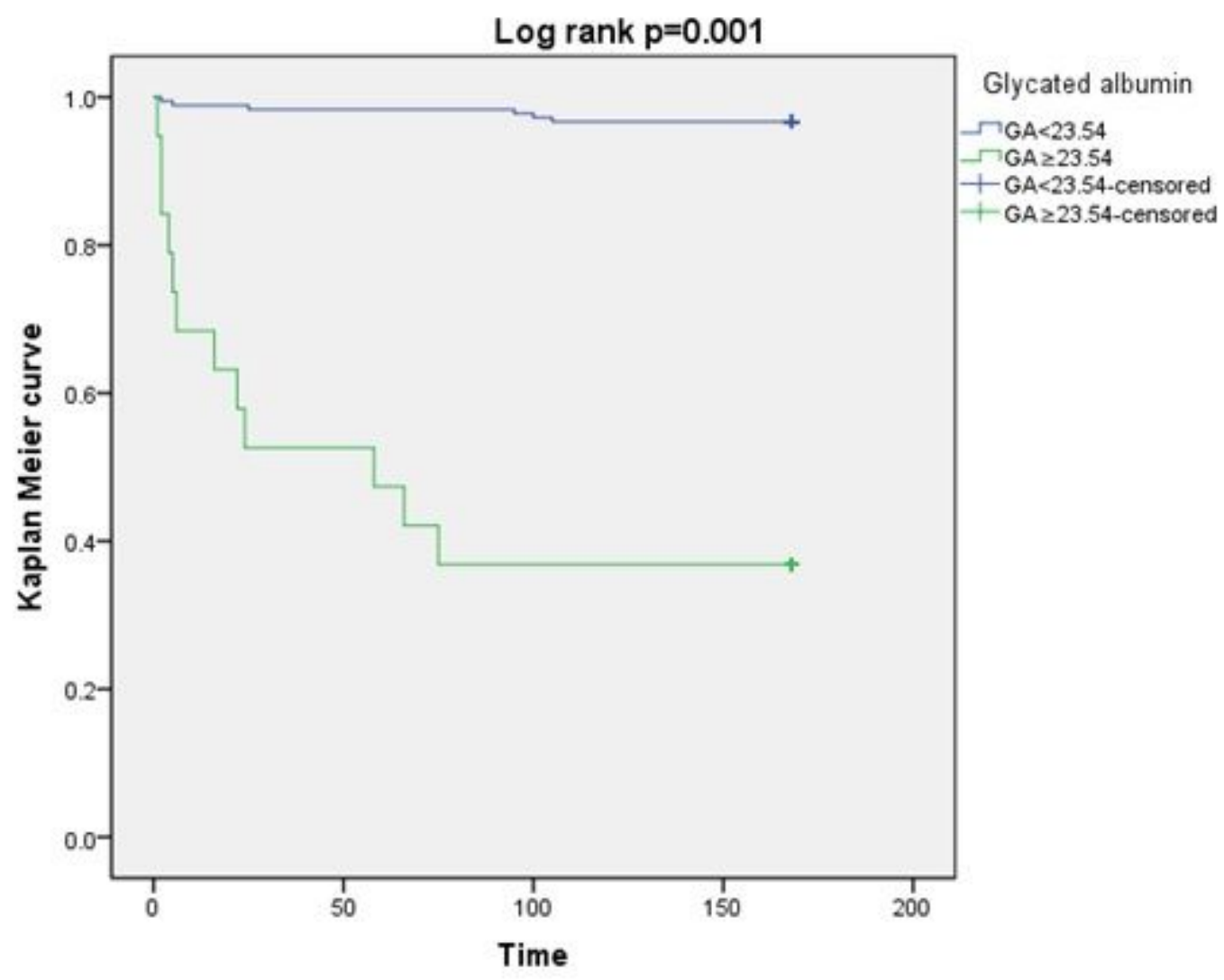

Figure 2

Figure 2

Kaplan Meier curve of GA. We conducted K-M curveand log rank test for cumulative incidence of inhospital MACEs of GA ( $p=0.001)$. General observation time is 7 days (168 hours). 


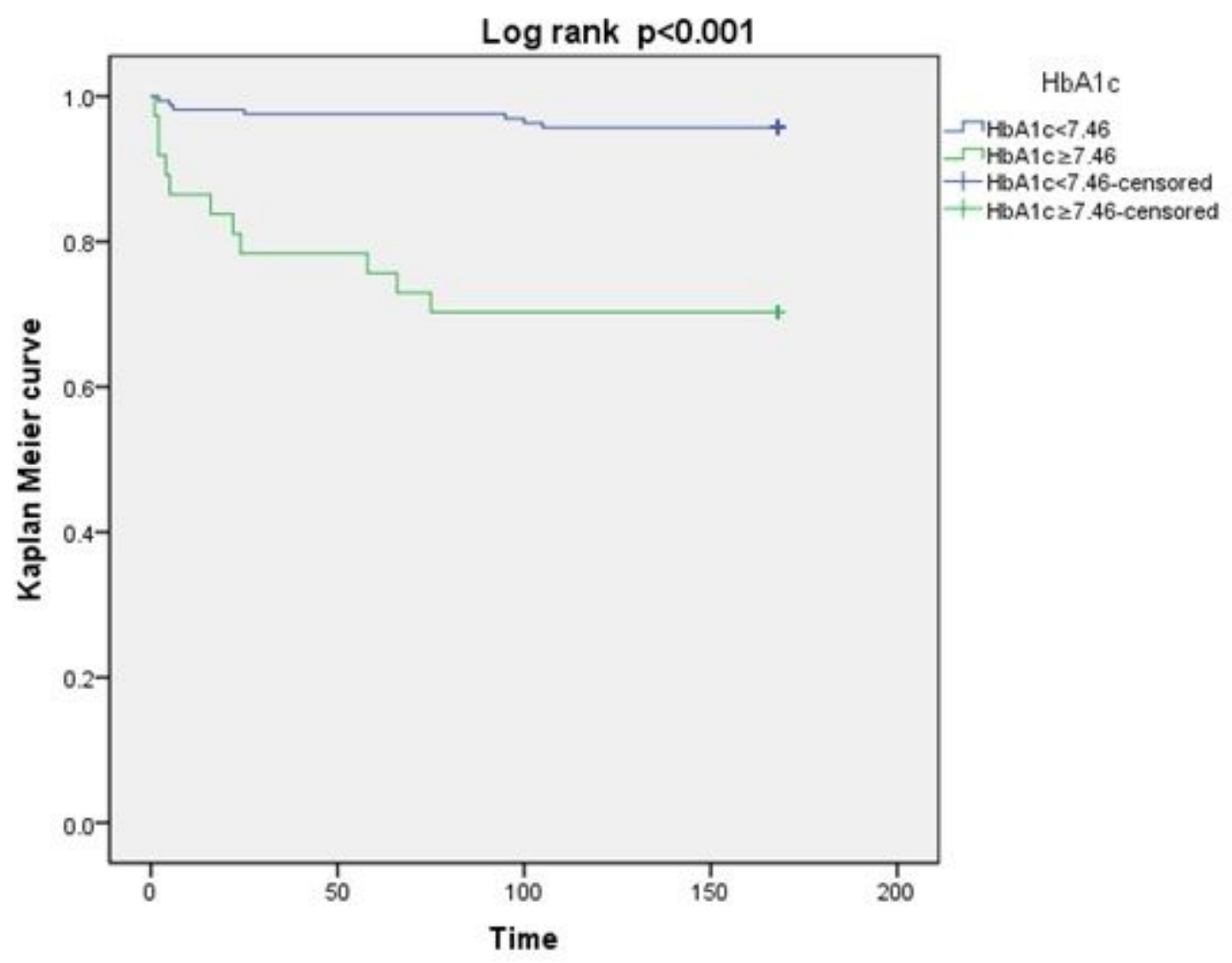

Figure 3.

\section{Figure 3}

Kaplan Meier curve of HbA1c. We conducted K-M curve and log rank test for cumulative incidence of inhospital MACEs of HbA1c $(p<0.001)$. General observation time is 7 days (168 hours). 


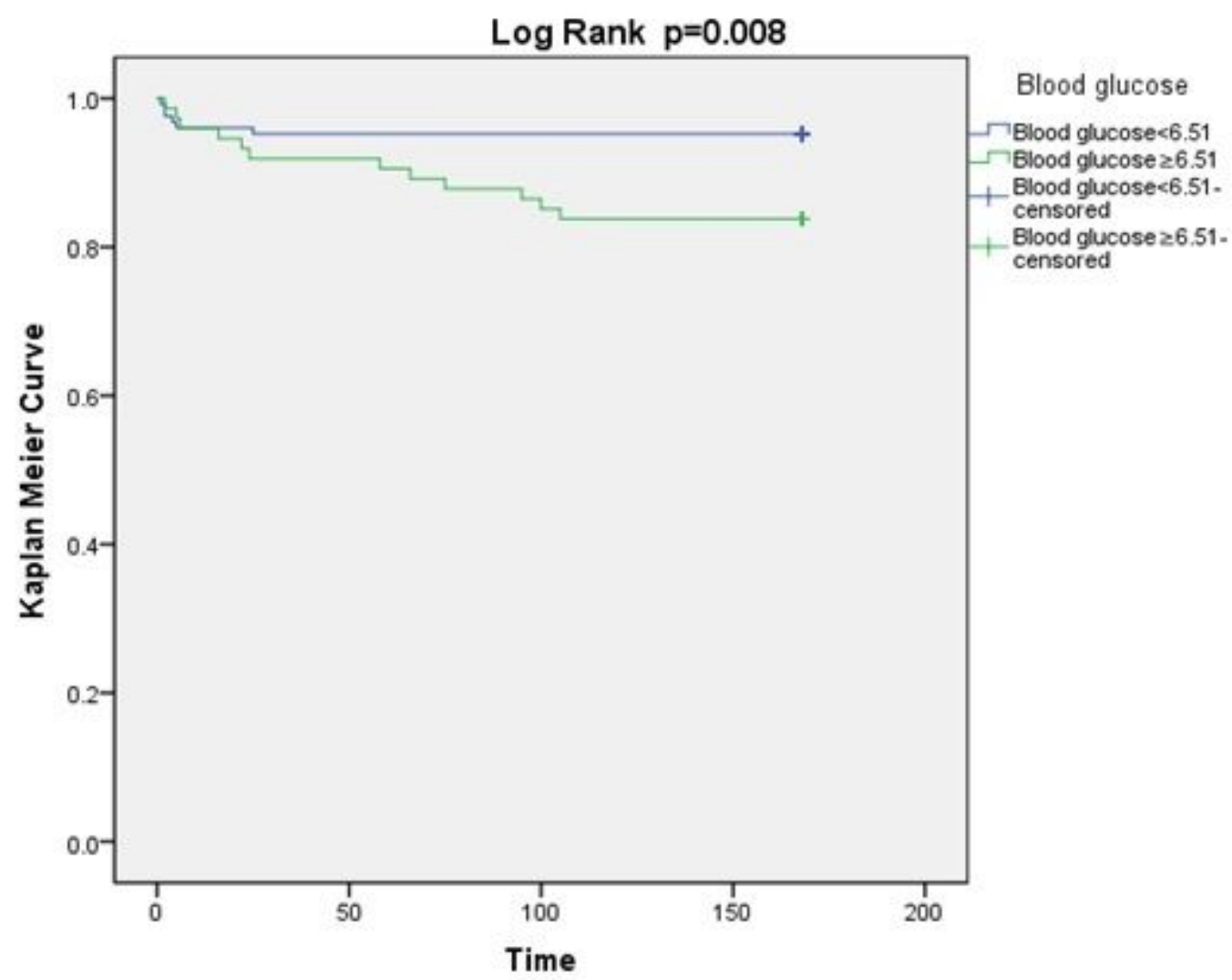

Figure 4.

\section{Figure 4}

Kaplan Meier curve of ABG. We conducted K-M curve and log rank test for cumulative incidence of inhospital MACEs of ABG ( $p=0.008)$. General observation time is 7 days (168 hours). 